NASZA DERMATOLOGIA Online OUR DERMATOLOGY Online

Source of Support: Nil

Competing Interests: None

\section{CLINICAL EVALUATION OF DIFFERENT THERAPEUTIC MODALITIES IN PSORIASIS BY PASI SCORE}

\author{
Neerja Puri ${ }^{1}$, Bharat Bhushan Mahajan ${ }^{1}$, Samarjeet Kaur Sandhu ${ }^{2}$ \\ ${ }^{1}$ Department of Dermatology and Venereology, Punjab Health Systems Corporation, \\ Ferozepur, Punjab, India \\ ${ }^{2}$ Department of Pathology, G.G.S. Medical College \& Hospital, Faridkot, 151203, \\ Punjab, India
}

Corresponding author: Dr. Neerja Puri

neerjaashu@rediffmail.com

\begin{abstract}
Psoriasis is a chronic recurrent papulosquamous disorder characterized by epidermal hyperplasia. The management of psoriasis can be challenging. Although, there are many therapeutic modalities available but still there are no clear cut guidelines regarding the usage of different modalities depending on the severity of psoriasis evaluated by PASI score. Taking this into consideration, a randomized controlled trial was undertaken to clinically evaluate different therapeutic modalities in psoriasis by PASI scoring. We selected fifty clinically diagnosed cases of psoriasis and confirmed by histopathology. The patients were put on different modalities depending on the psoriasis area and severity index score (PASI score) and all the patients were followed up to 24 weeks for any relapse.
\end{abstract}

Key words: psoriasis; PASI; treatment; diagnosis; methotrexate; retinoids; cyclosporine

\section{Introduction}

Psoriasis $[1,2]$ is a papulosquamous disorder charcterised by increased mitotic activity of the basal cell layer which results in rapid epidermal cell turnover with the 28 day normal epidermal cell cycle reduced to 5 days. Primary treatment goals for patients with psoriasis are: (1) reduce the size, thickness, and extent of plaque, papules, and erythema; and (2) improve quality of life (physical, mental, emotional, and social functioning). The measure of response to therapy (i.e., reduction in symptoms) is generally based on psoriasis area and severity index (PASI) score. A reduction of 50 percent from pretreatment baseline scores is generally accepted as a positive physical response; a reduction of 75 percent or more is generally accepted as a superior response approaching clearance. Though the diagnosis of psoriasis is clinical but still histopathological changes precede the clinical relapse [3].

Several factors influence therapeutic selections for patients with mild-to-moderate disease [4]. First and foremost, the nature of individual lesions (e.g., thick versus thin plaques) as well as the location and extent of distribution of plaques drive treatment decisions. Thereafter, therapeutic success, duration of remission, frequency of relapse, and appearance or desired avoidance of side effects dictate choices [5]. Finally, patient preference must be considered because some therapies are cosmetically inelegant (e.g., topical ointments and creams) or stain skin, clothing, bed linens, and bathtubs (e.g., anthralin); others are time consuming (e.g., broadband ultraviolet A and B phototherapies) or somewhat intolerable (e.g., intralesional injections, especially for nails).

According to treatment guidelines from the American Academy of Dermatology [6] (AAD), therapeutic intervention for localized mild-to-moderate plaque psoriasis should begin with patient education [7] and the use of topical corticosteroids with or without coal tar or calcipotriene. Thereafter, anthralin or tazarotene [8], alone or in combination with steroids, can be used following firstline treatment failure or subsequent loss of response to firstline therapy. Alternatively, if control is difficult to achieve or disease is widespread, phototherapy, with and without drugs such as psoralen or retinoids, may be required. In actual practice, therapies are often rotated $[9,10]$ to take advantage of unique features and benefits, to minimize the development of adverse events, or to avoid tachyphylaxis that may be associated with individual alternatives. More potent systemic therapies, such as methotrexate, cyclosporine, and the biologics, are sometimes required for severe psoriasis. The course is usually chronic and marked by remissions and relapses. 
Although no cure is available, but the disease can be effectively controlled by various topical and systemic treatment modalities alone or in combination. Mainstay of topical therapy includes coal tar, keratolytics, topical steroids, calcipotriol and tazarotene [11]. Most patients can be managed with topical [12] treatment alone. Systemic therapy is indicated in patients with moderate to severe psoriasis, variably having patients with PASI score more than 10.The different modalities available are mrethotrexate, retinoids, systemic PUVA, cyclosporine, hydroxyurea, sulfasalazine and mycophenolic acid.

\section{Aims}

To study the therapeutic efficacy of various modalities in psoriasis i.e. topical therapy, methotrexate, PUVA, retinoids and cyclosporine.

1. To do clinical evaluation by PASI scoring in psoriasis.

\section{Material and Methods}

For the present study, fifty clinically diagnosed cases of psoriasis were selected from the outpatient department of Dermatology,venereology and leprosy, Guru Gobind Singh Medical College and Hospital, Faridkot. All the patients were subjected to the following investigations:

1. Routine Investigations:

- Haemoglobin assessment, complete blood count, Fasting blood sugar, erythrocyte sedimentation rate and urine complete examination, ASO titre and throat swab for culture.

\section{Specialized investigations :}

- Biochemical Investigations - These include SGOT, SGPT, Serum Alkaline Phosphatase, Serum Uric acid, Blood urea, Serum creatinine, Total \& Differential serum Proteins and Serum calcium.

- Histopathological Investigations - in the form of Skin Biopsy.

The grouping of the patients was done depending on the PASI score. A written informed consent was taken from all the patients before starting the study. Prior approval of hospital ethical committee was taken for the study. PASI score was calculated in all patients at the start of study and then every 2 weekly till the remission phase of the disease. Patients were put on various treatment modalities depending on the PASI score. All patients were subjected to histopathological examination at the start of treatment and the biopsy was repeated at 8 weeks. The patients were evaluated at $0,2,4,6$ and 8 weeks and all patients were photographed. After 8 weeks, no treatment was given and the patients were asked to come for follow up every 4 weeks upto 24 weeks to see for any relapse.

The psoriasis area and severity index (PASI Score) was recorded in all the patients. The severity of erythema, scaling and induration was recorded on a scale from 0 to 4 .

$$
\begin{array}{lll}
0 & -- & \text { None } \\
1 & -- & \text { Mild } \\
2 & -- & \text { Moderate } \\
3 & -- & \text { Severe } \\
4 & -- & \text { Very Severe }
\end{array}
$$

The formula for calculating PASI score is as follows:

PASI score $=0.1(\mathrm{Eh}+\mathrm{I} \mathrm{h}+\mathrm{D} \mathrm{h}) \mathrm{x} \mathrm{A} \mathrm{h}+0.2(\mathrm{Eu}+\mathrm{Iu}+\mathrm{Du}) \mathrm{x}$ $\mathrm{Au}+0.3(\mathrm{Et}+\mathrm{It}+\mathrm{Dt}) \times \mathrm{At}+0.4(\mathrm{EL}+\mathrm{IL}+\mathrm{DL}) \times \mathrm{AL}$

Ah means area of head involved in psoriasis.

$\mathrm{Au}$ means area of upper limb involved in psoriasis.

At means area of trunk involved in psoriasis.

AL means area of lower limb involved in psoriasis.

We calculated the area involved by psoriasis as follows:

$1=$ Less than $10 \%$ area involved

$2=10-29 \%$ area involved

$3=30-49 \%$ area involved

$4=50-69 \%$ area involved

$5=70-89 \%$ area involved

$6=90 \%$ or more area involved

The grouping of the patients was done depending on the PASI score.

Group I - Patients having PASI score less than 10. These patients were put on topical therapy. Topical therapy included emollients, topical salicylic acid $(3 \%)$ in Betamethasone valerate $(0.12 \%)$ and topical calcipotriol.

Group II - Patients having PASI score between 10-20. These patients were put on PUVA therapy alone.

Group III - Patients having PASI score more than 20. These patients were put on methotrexate, cyclosporine or Acitretin, depending on the cost effectiveness, compliance and lipid profile.

Patients were followed up after every 2 weeks. PASI scoring was done at each visit. Complete physical examination, blood pressure recording, haemogram, urine examination,liver function tests and kidney function tests were done at each visit.

\section{Inclusion Criteria}

Subjects of both sexes irrespective of their age having psoriasis.

\section{Exclusion criteria}

The following patients were excluded from our study:

- Patients with impaired renal function/ preexisting renal disease.

- Patients with acute uncontrolled bacterial, viral or fungal infection.

- Patients on concomitant use of hepatotoxic or nephrotoxic drugs for any other long standing illness.

- Pregnant/ breast feeding females.

- Concurrent immunodeficiency state.

- Uncontrolled hypertension.

- Patients having hepatitis, active or recent

Patients having severe anaemia, leukopaenia or thrombocytopenia.

- Patients having excessive alcohol consumption.

\section{Results}

The data was tabulated and the results were analysed statistically. 


\section{Age Distribution}

The above table shows that maximum number of cases (22\%) were in the age group of 51-60 years. It was followed by $20 \%$ in the age group of $31-40$ years, $18 \%$ in the age group 21-30 years, $16 \%$ in the age group $41-50$ years, $16 \%$ in the age group 11-20 years, $12 \%$ in the age group $0-10$ years and $8 \%$ of the cases were above 60 years of age. Mean age of psoriasis in our patients was $38.46+3.287$ (Tabl. I).

\begin{tabular}{|l|l|l|}
\hline \multicolumn{1}{|c|}{ Age } & Number of patients & \multicolumn{1}{c|}{ Percentage } \\
\hline $0-10$ & 2 & $4 \%$ \\
\hline $11-20$ & 6 & $12 \%$ \\
\hline $21-30$ & 9 & $18 \%$ \\
\hline $31-40$ & 10 & $20 \%$ \\
\hline $41-50$ & 8 & $16 \%$ \\
\hline $51-60$ & 11 & $22 \%$ \\
\hline$>60$ & 4 & $8 \%$ \\
\hline TOTAL & 50 & $100 \%$ \\
\hline
\end{tabular}

Table I. Incidence of psoriasis among different age groups

\section{Sex Distribution}

The above table shows that out of 50 psoriatics, $31(62 \%)$ were males, while $19(38 \%)$ were females. Male to female ratio was 1.63: 1 (Tabl. II).

\begin{tabular}{|l|l|l|}
\hline \multicolumn{1}{|c|}{ Sex } & \multicolumn{1}{c|}{ Number of patients } & \multicolumn{1}{c|}{ Percentage } \\
\hline Male & 31 & $62 \%$ \\
\hline Female & 19 & $38 \%$ \\
\hline Total & 50 & 100 \\
\hline
\end{tabular}

\section{Total Duration of Psoriasis}

The above table shows that the duration of the psoriasis was less than 5 years was seen in $66 \%$ of cases, between 5 and
10 years in $26 \%$ of cases, between 11 and 15 years in $6 \%$ of cases, between 16 and 20 years in $2 \%$ of cases. The mean duration of disease in our study was $4.74+14.64$ in our study (Tabl. III).

\begin{tabular}{|l|l|l|}
\hline Duration of psoriasis (in years) & \multicolumn{1}{|c|}{ Number of cases } & Percentage \\
\hline Less than 5 years & 33 & 66 \\
\hline Between 5-10 years & 13 & 26 \\
\hline Between 11-15 years & 3 & 6 \\
\hline Between 16-20 years & 1 & 2 \\
\hline Total & 50 & 100 \\
\hline
\end{tabular}

\section{Triggering Factors in Psoriasis}

The above table shows various triggering factors in psoriasis patients. The commonest triggering factor in psoriasis patients was stress seen in $24(48 \%)$ patients. Trauma as a triggering factor was seen in $10(20 \%)$ patients, drug intake in $18(36 \%)$ patients, alcoholism in $16(32 \%)$ patients and sunlight as a triggering factor was seen in $3(6 \%)$ patients (Tabl. IV).

In our study, the grouping of patients was done depending on the PASI score.
Group I - Group I patients had PASI score less than 10. Group I patients were subdivided into 3 subgroups:

Subgroup (i) - Patients were given only emollients. Number of patients in this group were 2 .

Subgroup (ii) - Patients were given topical salicylic acid $(3 \%)$ in Betamethasone valerate $(0.12 \%)$. Number of patients in this group were 4.

Subgroup (iii) - Patients were given topical calcipotriol $(0.005 \%)$ in dose of $50 \mu \mathrm{gm} / \mathrm{gm}$ and was applied twice daily. Number of patients in this group were 3 . 
Group II - Group II patients had PASI score between 1020. These patients were put on PUVA therapy. Patients were given 8 methoxypsoralen in a dose of $0.6 \mathrm{mg} / \mathrm{kg} /$ day on every alternate day and then patients were exposed to UVA after 2 hours. Number of patients in this group were 12 .

Group III - Group III patients had PASI score more than 20. Total number of patients in this group were 29. These patients were subdivided into 3 subgroups:
Subgroup (i) - Patients were put on methotrexate (16 patients). Methotrexate was given in dose of $0.2 \mathrm{mg} / \mathrm{kg}$ body weight/ week in 3 divided doses depending upon the severity of psoriasis.

Subgroup (ii) - Patients were put on Acitretin (10 patients). Acitretin was given in dose of $0.5 \mathrm{mg} / \mathrm{kg}$ body weight/ day. Subgroup (iii) - Patients were put on cyclosporine (3 patients). Cyclosporine was given in dose of $3 \mathrm{mg} / \mathrm{kg} /$ day.

\begin{tabular}{|l|l|l|l|}
\hline No & $\begin{array}{c}\text { Triggering factors in } \\
\text { psoriatics }\end{array}$ & Number of cases & Percentage \\
\hline 1 & Stress & 24 & 48 \\
\hline 2 & Trauma & 10 & 20 \\
\hline 3 & Sore throat & 18 & 36 \\
\hline 4 & Alcoholism & 16 & 32 \\
\hline 5 & Drug intake & 18 & 36 \\
\hline 6 & Photo aggravation & 3 & 6 \\
\hline
\end{tabular}

Table IV. Triggering factors in psoriasis patients

\section{Grouping of Patients (Tabl. V)}

\begin{tabular}{|c|l|l|l|l|l|l|l|}
\hline \multicolumn{1}{|c|}{ No } & \multicolumn{2}{|l|}{ Group I (Topical therapy) PASI < 10 } & \multicolumn{1}{c|}{$\begin{array}{l}\text { Group II } \\
\text { (PASI 10-20) }\end{array}$} & \multicolumn{2}{c|}{ Group III (PASI > 20) } \\
\hline & $\begin{array}{l}\text { Subgroup (i) } \\
\text { (Emollients) }\end{array}$ & $\begin{array}{l}\text { Subgroup (ii) } \\
\text { topical salicylic } \\
\text { acid (3\%) in } \\
\text { Betamethasone } \\
\text { valerate (0.12\%) }\end{array}$ & $\begin{array}{l}\text { Subgroup } \\
\text { (iii) } \\
\text { (Topical } \\
\text { calciptriol) }\end{array}$ & PUVA therapy & $\begin{array}{l}\text { Subgroup (i) } \\
\text { (Methotrexate) }\end{array}$ & $\begin{array}{l}\text { Subgroup } \\
\text { (ii) } \\
\text { (Retinoids) }\end{array}$ & $\begin{array}{l}\text { Subgroup (iii) } \\
\text { (Cyclosporin) }\end{array}$ \\
\hline $\begin{array}{l}\text { No. of } \\
\text { patients }\end{array}$ & 2 & 4 & 3 & 12 & 16 & 10 & 3 \\
\hline
\end{tabular}

Table V. Grouping of patients depending on PASI score

\section{PASI Score}

The above table shows that in all the groups the mean reduction of PASI score was statistically significant (Tabl. VI).

\begin{tabular}{|c|c|c|c|c|c|c|c|}
\hline \multirow[b]{2}{*}{ Groups } & \multicolumn{6}{|c|}{ Mean PASI SCORE } & \multirow[b]{2}{*}{ Significance } \\
\hline & $\begin{array}{l}\text { AT } 0 \\
\text { WKS }\end{array}$ & $\begin{array}{l}\text { AT } 2 \\
\text { WKS }\end{array}$ & $\begin{array}{l}\text { AT } 4 \\
\text { WKS }\end{array}$ & $\begin{array}{l}\text { AT } 6 \\
\text { WKS }\end{array}$ & $\begin{array}{l}\text { AT } 8 \\
\text { WKS }\end{array}$ & $\begin{array}{l}\text { Mean } \% \text { age } \\
\text { reduction in } \\
\text { PASI }\end{array}$ & \\
\hline Gropu I Subgroup (i) (Emollients) & 8.2 & 7.8 & 6.9 & 5.1 & 4.0 & PASI 50 & $\begin{array}{l}t=4.91 \\
p>0.05(S)\end{array}$ \\
\hline $\begin{array}{l}\text { Subgroup (ii) (Topical salicylic acid } \\
(3 \%) \text { in Betamethasone valerate }(0.12 \%)\end{array}$ & 8.7 & 7.7 & 6.2 & 4.4 & 2.3 & PASI 75 & $\begin{array}{l}\mathrm{t}=2.98 \\
\mathrm{p}>0.05(\mathrm{~S})\end{array}$ \\
\hline Subgroup (iii) (Topical calcipotrol) & 9.8 & 8.2 & 7.3 & 5.1 & 2.4 & PASI 75 & $\begin{array}{l}t=3.14 \\
p>0.05(S)\end{array}$ \\
\hline Group II (PUVA) & 20 & 17.2 & 15.4 & 12.2 & 9.2 & PASI 50 & $\begin{array}{l}t=3.68 \\
p>0.05(S)\end{array}$ \\
\hline Group III Subgroup (i) (Methotrexate) & 42.5 & 31.7 & 27.2 & 18.6 & 10.4 & PASI 75 & $\begin{array}{l}\mathrm{t}=4.37 \\
\mathrm{p}>0.05(\mathrm{~S})\end{array}$ \\
\hline Subgroup (ii) (Acitretin) & 34.8 & 30.4 & 25.2 & 19.1 & 16.9 & PASI 50 & $\begin{array}{l}\mathrm{t}=3.89 \\
\mathrm{p}>0.05(\mathrm{~S})\end{array}$ \\
\hline Subgroup (iii) (Cyclosporin) & 35.6 & 30.2 & 24.4 & 18.1 & 8.5 & PASI 75 & $\begin{array}{l}\mathrm{t}=3.29 \\
\mathrm{p}>0.05(\mathrm{~S})\end{array}$ \\
\hline
\end{tabular}




\section{Relapse in Psoriasis}

So, from the above table, it is clear that mean $75 \%$ reduction in PASI score was achieved with methotrexate (Fig. 1), cyclosporine (Fig. 2), topical corticosteroids and topical calcipotriol, whereas mean 50\% reduction in PASI score was achieved with PUVA therapy (Fig. 3), oral retinoids (Fig. 4), and emollients at 8 weeks. During the follow up period upto 24 weeks, relapse was seen in $2 \%$ patients. On emollients, topical corticosteroids and PUVA therapy each and 4\% patients on retinoids. But no patient on topical calcipotriol, methotrexate or cyclosporin showed any relapse up to 24 weeks (Tabl. VII).

\begin{tabular}{|l|l|l|l|}
\hline \multicolumn{1}{|c|}{ Drug } & Total no. of cases & $\begin{array}{c}\text { No. of cases } \\
\text { showing relapse }\end{array}$ & $\begin{array}{l}\text { \% age of patients } \\
\text { with relapse }\end{array}$ \\
\hline Emollients & 2 & 1 & $2 \%$ \\
\hline $\begin{array}{l}\text { Topical salicylic acid (3\%) in Betamethasone } \\
\text { valerate (0.12\%) }\end{array}$ & 4 & 1 & $2 \%$ \\
\hline PUVA & 12 & 1 & $2 \%$ \\
\hline Acitretin & 10 & 2 & $4 \%$ \\
\hline Others & 26 & - & - \\
\hline Total & 50 & 5 & $10 \%$ \\
\hline
\end{tabular}

Table VII. Age (\%) of patients with relapse.

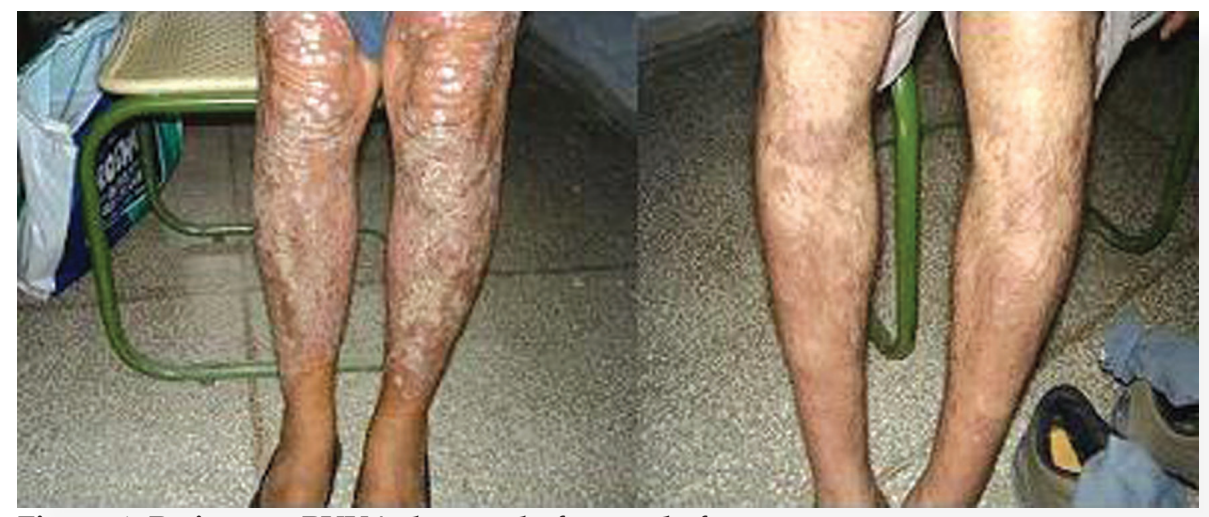

Figure 1. Patient on PUVA therapy before and after treatment

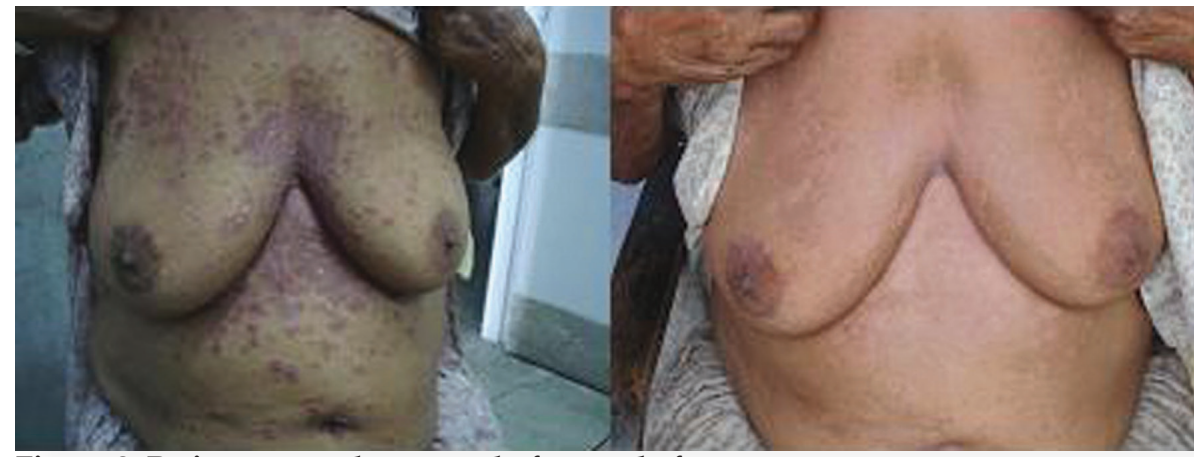

Figure 2. Patient on methotrexate before and after treatment

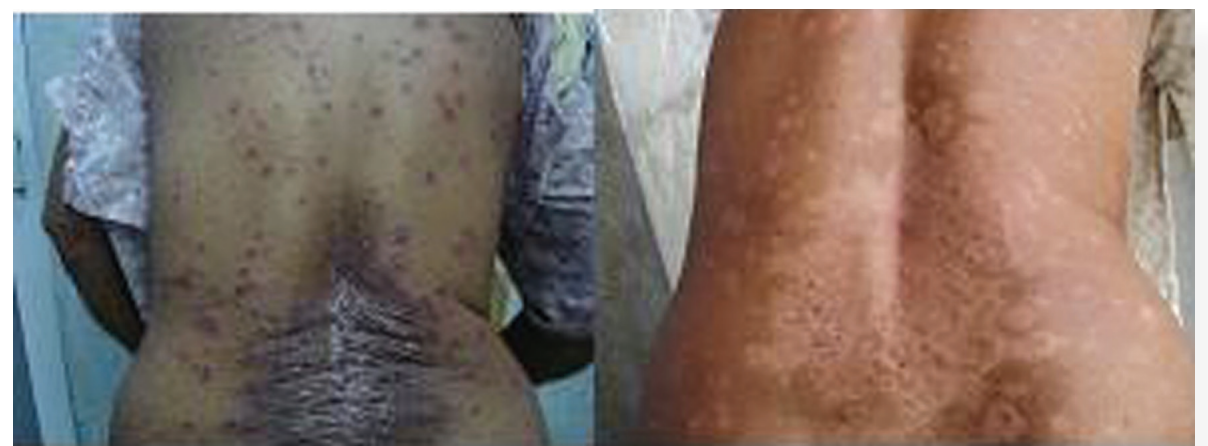

Figure 3. Patient on acitretin before and after treatment 


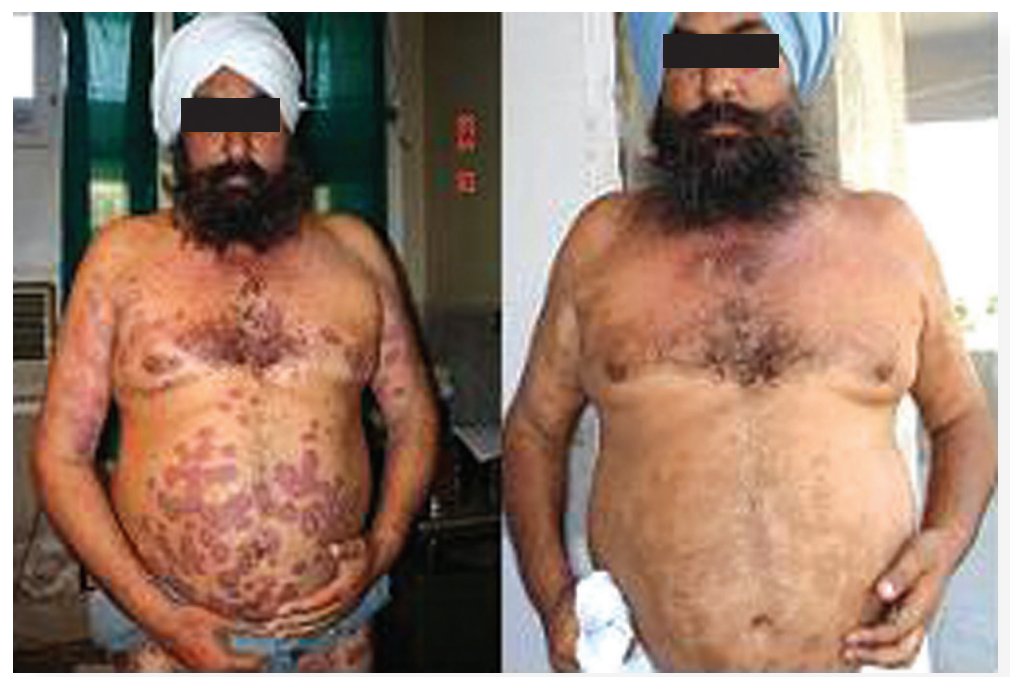

Figure 4. Patient on cyclosporine before and after treatment

\section{Discussion}

Although psoriasis is rarely life threatening, it can cause significant morbidity, social embarrassment and financial cost and disruption in patients life; while patients with extensive and severe disease may require systemic therapy, less severe psoriasis is typically treated with topical medications [12]. The management of psoriasis can be challenging on several levels [13]. For patients and providers, resolution of disease is the primary therapeutic objective. Complete and prolonged clearance is the preferred outcome, but one that is elusive in almost all cases. For payers, cost control is vital, so treatment regimens that are less costly or more cost-effective are favored.

For patients with PASI score less than 10, topical corticosteroids [14], with relatively low acquisition costs, are the mainstay of first-line care but can be problematic when used alone. Their onset of action is fast, but exacerbation of disease can also be rapid upon treatment discontinuation. Side effects, such as telangiectasia, striae, epidermal thinning, scar extension, acne, glaucoma, and suppression of hypothalamus-pituitary-adrenal [15] activity are concerns. Moreover, over time effectiveness is lost. For these reasons, the more expensive calcipotriene [16] or possibly tazarotene is commonly combined with a topical corticosteroid for initial disease management. The combination is beneficial for the majority of patients but must be used almost continuously, uninterrupted, or pulsed, to achieve and then maintain a response after successful disease control. Continuous daily or twice-daily applications of one or more creams or ointments can be time consuming, cosmetically inelegant, and objectionable for many patients, especially during work days. Because treatment is continuous, disease control can be prolonged, but treatment-free days are rare. For this reason, cost effectiveness varies according to the outcome that is measured.

Retinoids [17] by themselves, with no additional therapy, are generally ineffective for most forms of psoriasis. Required doses cause significant side effects, such as hair loss, nail thinning, dried and chapped mucous membranes and skin, and hyperlipidemia [18]. The most serious problem associated with retinoid [19] utilization are birth defects in the offspring of women who use these drugs before or during pregnancy. Retinoids can be effective, however, when used judiciously in very low doses in combination with ultraviolet light.

Phototherapies [20], including UVB, UVA plus psoralen (PUVA), are the final options for second-line treatments that are considered in this health economic assessment. According to the American Academy of Dermatology guidelines, these interventions are useful for patients with lesions that are limited but refractory to topical agents, lesions that are widespread, or when disruption of daily activities or employment compromise patient well-being. Logically, UVB and PUVA have more utility when disease is widespread; whereas, the excimer laser is more suitable when disease is more contained. For these reasons, phototherapies are selectively used on different patient populations rather than generally used for all patients who fail first-line care. Cyclosporine and methotrexate are highly effective drugs in the treatment of severe psoriasis. Methotrexate [21] is a folic acid antagonist which exerts antimitotic action on the epidermis by inhibiting DNA synthesis. Over four decades of experience has established methotrexate as a standard therapy in psoriasis despite its side effects. Methotrexate is indicated in the symptomatic control of patients with moderate to severe psoriasis not responding to topical therapy, patients with erythroderma, palmoplantar pustulosis, generalized pustular psoriasis and psoriatic arthritis. Important contraindications of methotrexate include significant abnormalities in renal and hepatic function, hepatitis (active or recent), cirrhosis, pregnancy, lactation, male or female fertility, immunodeficiency state, excessive alcohol consumption and non compliant patient.

Cyclosporine [22] is a lipophitic cyclic undecapeptide and it inhibits the production of several limphokines including IL-2 bt $\mathrm{T}$ cells. Besides extensive severe psoriasis, cyclosporine has also been used in localized, severe and disabling forms of psoriasis like acrodermatitis continua, palmoplantar pustulosis and recalcitrant generalized pustular psoriasis. Its efficacy is somewhat marred by dose related but reversible side effects namely hypertension and renal dysfunction.

In our study, PASI 75 was achieved in patients on methotrexate, cyclosporine, topical corticosteroids (plus emollients and keratolytics) and topical calcipotriol. 
PASI 75 is defined as a reduction from baseline PASI score of $>75 \%$. PASI 75 is used as the benchmark of primary end points in assessing therapies for psoriasis. Patients reaching PASI 75 experience very meaningful changes in psoriasis severity. The change in quality of life (QoL) in patients reaching PASI 75 is essentially that of the patient who achieves clear to almost clear status. These days, PASI 50 (or a reduction in PASI score of 75\%). These days, PASI 50 [23] is used to assess severity of psoriasis, as many consider PASI 75 as an end point which is too stringent as it places potentially useful therapies at risk of failing to demonstrate efficacy. In our study, PASI 50 was achieved in patients on PUVA therapy, Acitretin and emollients. At the same time, assessment of psoriasis using PASI score has certain drawbacks. An improvement in PASI score [24] does not correlate in a 1:1 ratio with improvement in disease and can underestimate improvement.

In our study it was seen that $5(10 \%)$ patients on PUVA therapy. Acitretin and emollients, showed relapse after stopping the treatment at 8 weeks. Subsequently, it was advised that these patients be put on a combination of drugs in a rotational manner rather than on single drug to increase efficacy, reduce side effects and decreasing the chances of relapse. The patients who went into relapse were put on combination therapy. Hence, it is recommended that all the patients be put on combination therapy on a rotational basis to prolong the remission period. Also, a long term follow up is required to evaluate the exact efficacy of different modalities.

\section{Conclusions}

Despite limitations, the PASI score remains the most accepted and widely used measure in clinical trials. PASI, however, is rarely used by dermatologists in clinical practice and most are unaware of its significance or how to interpret changes seen in PASI score in clinical trials. Thus, to interpret the literature and to present results of clinical trials to patients and colleagues, it is imperative that dermatologists, researchers and reviewers understand what level of PASI reduction is clinically meaningful for patients. Also, to reduce side effects, improve efficacy and cost effectiveness, combination therapy on a rotational basis is advised in patients of psoriasis. Further, a large randomized controlled multicentric trial is required to formulate the guidelines for various therapeutic modalities to be used, depending on the severity of psoriasis evaluated by PASI score.

\section{REFERENCES}

1. Krueger GG, Bergstresser PR, Lowe NJ, Voorhess JJ, Weinstein GD: Psoriasis. J Am Acad Dermatol. 1984;11: 937-47.

2. Camp RDR: Psoriasis. In: Champion RH, Burton JL, Burns DA, Breathnach SM, editors. Textbook of dermatology. 6th ed., Vol. 3. Oxford: Blackwell Scientific Publications; 1998. p.1589-49.

3. De Arruda LHF, De Morales APF: The impact of psoriasis on quality of life. BJD. 2001;144(suppl 58):21-5.
4. Feldman SR: Psoriasis treatment. Curr Prob Dermatol. 1998;10:140.

5. Linden KG, Weinstein GD: Psoriasis: current perspectives with an emphasis on treatment. Am J Med. 1999;107:595-605.

6. American Academy of Dermatology. Committee on Guidelines of Care, Task Force on Psoriasis. Guidelines of care for psoriasis. J Am Acad Dermatol. 1993;28:632-7.

7. Linden KG, Weinstein GD: Psoriasis: current perspectives with an emphasis on treatment. Am J Med. 1999;107:595-605 .

8. Weinstein GD, Krueger GG, Lowe NJ, Duvic M, Freidman DJ, Jegasothy BV, et al: Tazarotene gel, a new retinoid for topical therapy of psoriasis: vehicle-controlled study of safety, efficacy, and duration of therapeutic effect. J Am Acad Dermatol. 1997;37:85-92. 9. Koo J: Sequential therapy for psoriasis. NPF Psoriasis Forum. 1998;4:3.

10. Koo J: Systemic sequential therapy of psoriasis: a new paradigm for improved therapeutic results. J Am Acad Dermatol. 1999;41:S258.

11. Krueger GG, Drake LA, Elias PM, Lowe NJ, Guzzo C, Weinstein GD, et al: The safety and efficacy of tazarotene gel, a topical acetylenic retinoid, in the treatm of psoriasis. Arch Dermatol. 1998;134:57-60.

12. Lebwohl M, Abel E, Zanolli M, Koo J, Drake L: Topical therapy for psoriasis. Int J Dermatol. 1995;34: 673-84.

13. Al-Suwaidan SN, Feldman SR: Clearance is not a realistic expectation of psoriasis treatment. J Am Acad Dermatol. 2000;42:796 -802.

14. Fredriksson T, Lassus A, Salde L: Reproducibility of clinical trials of topical gloucocorticosteriods. Int J Dermatol. 1983;22:5369.

15. Walsh P, Aeling JL, Huff L, Weston WL: Hypothalamuspituitary-adrenal axis suppression by superpotent topical steroids. J Am Acad Dermatol. 1993;29:501-3.

16. Dubertret L, Wallach D, Souteyrand P, Perussel M, Kalis B, Meynadier J, et al: Efficacy and safety of calcipotriol (MC 903) ointment in psoriasis vulgaris: a randomized, double-blind, right/left comparative vehicle-controlled study. J Acad Dermatol. 2992;27(6 pt 1):983-8.

17. Goldfarb MT, Ellis CN, Voorhees JJ: Short-term and longterm considerations in the management of psoriasis with retinoids. Dermatologica. 1987;175:100-6.

18. Ellis CN, Swanson NA, Grekin RC, Goldstein NG, Bassett DR, Anderson TF, et al. Etretinate therapy causes increases in lipid levels in patients with psoriasis. Arch Dermatol. 1982;118:559-62.

19. Ellis CN, Voorhees JJ: Etretinate therapy. J Am Acad Dermatol. 1987;16:267-91.

20. Henseler T, Wolff K, Hönigsmann H, Christophers E: Oral8methoxypsoralen photochemotherapy of psoriasis. European PUVA Study: A cooperative study among 18 European centres. Lancet. 1981.1:853.

21. Roenigk HH Jr, Auerbach R, Maibach H, Weinstein G, Lebwohl M: Methotrexate in psoriasis: Consensus conference. J Am Acad Dermatol. 1998:38:478.

22. Mrowietz U, Färber L, Henneicke-von Zepelin HH, Bachmann $\mathrm{H}$, Welzel D, Christophers E: Long-term maintenance therapy with cyclosporine and post-treatment survey in severe psoriasis. results of a multicenter study. J Am Acad Dermatol. 1995:33:470.

23. Carlin CS, Feldman SR, Krueger JG, Menter A, Krueger GG: A $50 \%$ reduction in the Psoriasis Area and Severity Score (PASI 50) is a clinically significant endpoint in the assessment of psoriasis. J Am Acad Dermatol. 2004;50:859-66.

24.Langley RG, Ellis CN: Evaluating psoriasis with Psoriasis Area and Severity Index, Psoriasis Global Assessment, and Lattice System Physician's Global Assessment. J Am Acad Dermatol. 2004;51:563-9. 